\title{
Magnetopause reconnection across wide local time
}

\author{
M. W. Dunlop ${ }^{1,10,12}$, Q.-H. Zhang ${ }^{2}$, Y. V. Bogdanova ${ }^{3}$, K. J. Trattner ${ }^{4}$, Z. Pu ${ }^{5}$, H. Hasegawa ${ }^{6}$, J. Berchem ${ }^{7}$,

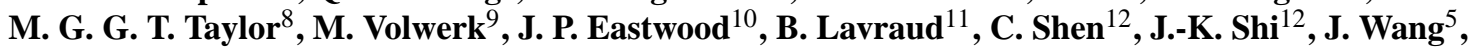

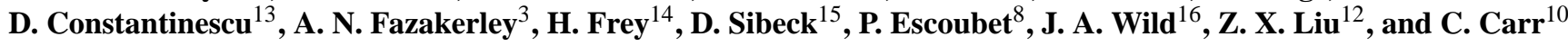 \\ ${ }^{1}$ SSTD, RAL, Chilton, DIDCOT, Oxfordshire, OX11 0QX, UK \\ ${ }^{2}$ SOA Key Laboratory for Polar Science, Polar Research Institute of China, Shanghai 200136, China \\ ${ }^{3}$ MSSL, University College London, Dorking, Surrey, RH5 6NT, UK \\ ${ }^{4}$ Lockheed Martin, Palo Alto, CA, USA \\ ${ }^{5}$ School of Earth and Space Sciences, Peking University, Beijing 100871, China \\ ${ }^{6}$ Institute of Space and Astronautical Science, JAXA, Japan \\ ${ }^{7}$ IGPP - UCLA, 3877 Slichter Hall, Los Angeles, CA 90095-1567, USA \\ ${ }^{8}$ ESA/ESTEC, Keplerlaan 1, 2200 AG Noordwijk, The Netherlands \\ ${ }^{9}$ Space Research Institute, Austrian Academy of Sciences, Schmiedlstr. 6, 8042 Graz, Austria \\ ${ }^{10}$ The Blackett Laboratory, Imperial College London, London, SW7 2AZ, UK \\ ${ }^{11}$ IRAP - CNRS, 9 Ave. du Colonel Roche, 31028 Toulouse Cedex 4, France \\ ${ }^{12}$ CSSAR, Chinese Academy of Sciences, Beijing 100190, China \\ ${ }^{13}$ Institut für Geophysik und Meteorologie, TU-BS, 38106 Braunschweig, Germany \\ ${ }^{14}$ Space Sciences Lab., University of California, 7 Gauss Way, Berkeley, CA 94720-7450, USA \\ ${ }^{15}$ Code 674, NASA/GSFC, Greenbelt, MD 20771, USA \\ ${ }^{16}$ Space Plasma Environment and Radio Science group, Lancaster University, LA1 4WA, UK
}

Received: 29 March 2011 - Revised: 27 July 2011 - Accepted: 2 September 2011 - Published: 29 September 2011

\begin{abstract}
During April to July 2007 a combination of 10 spacecraft provided simultaneous monitoring of the dayside magnetopause across a wide range of local times. The array of four Cluster spacecraft, separated at large distances $(10000 \mathrm{~km})$, were traversing the dawn-side magnetopause at high and low latitudes; the five THEMIS spacecraft were often in a $4+1$ grouped configuration, traversing the low latitude, dusk-side magnetosphere, and the Double star, TC-1 spacecraft was in an equatorial orbit between the local times of the THEMIS and Cluster orbits. We show here a number of near simultaneous conjunctions of all 10 spacecraft at the magnetopause. One conjunction identifies an extended magnetic reconnection X-line, tilted in the low latitude, sub-solar region, which exists together with active anti-parallel reconnection sites extending to locations on the dawn-side flank. Oppositely moving FTE's are observed on all spacecraft, consistent with the initially strong IMF $B_{\mathrm{y}}$ conditions and the comparative locations of the spacecraft both dusk-ward and dawn-ward of noon. Comparison with other conjunctions of magnetopause crossings, which are also distributed
\end{abstract}

Correspondence to: M. W. Dunlop (m.w.dunlop@rl.ac.uk) over wide local times, supports the result that reconnection activity may occur at many sites simultaneously across the sub-solar and flank magnetopause, but linked to the large scale (extended) configuration of the merging line; broadly depending on IMF orientation. The occurrence of MR therefore inherently follows a "component" driven scenario irrespective of the guide field conditions. Some conjunctions allow the global magnetopause response to IMF changes to be observed and the distribution of spacecraft can directly confirm its shape, motion and deformation at local noon, dawn and dusk-side, simultaneously.

Keywords. Magnetospheric physics (Magnetopause, cusp, and boundary layers) - Space plasma physics (Magnetic reconnection)

\section{Introduction}

The Earth's magnetopause and its surrounding boundary layers (magnetosheath boundary layer, low and high latitude boundary layers, and the polar cusps) are key areas for the study of solar wind-magnetosphere coupling across the dayside and flank magnetopause. Research in recent years

Published by Copernicus Publications on behalf of the European Geosciences Union. 
suggests that different plasma transport mechanisms can exist simultaneously at the magnetopause; controlled by conditions external to the magnetosphere. In particular, the clock angle (in the plane perpendicular to the sun-earth line) of the interplanetary magnetic field (IMF) is a critical parameter. For example, under southward IMF, or for orientations tilted away from purely southward, magnetic reconnection (MR, Dungey, 1961) is known to be the dominant dayside process transferring momentum and energy into the Earth's magnetosphere: depending on the shear angle between the adjacent magnetosheath and magnetospheric fields near the magnetopause. Previous investigations have probed its operation (location and rate) at the dayside magnetopause (e.g. Sonnerup, 1974; Sonnerup et al., 1981; Scurry and Russell, 1991; Dorelli and Raeder, 2005, 2007; Kessel et al., 1996; Lockwood and Smith, 1992; Lavraud and Borovsky, 2008; Borovsky, 2008), and also the associated location of the Earth's cusps (Lavraud et al., 2004, 2005a), although the large-scale properties of MR, such as the factors controlling its occurrence and the exact mechanism controlling transient reconnection, are still not very well understood. During purely northward IMF, the main transport process remains uncertain, since competing mechanisms may operate, such as dual lobe reconnection (Bogdanova et al., 2005, 2008; Onsager et al., 2001; Lavraud et al., 2005b, 2006), diffusion, and plasma transport via Kelvin-Helmholtz waves (Hasegawa et al., 2004a; Taylor and Lavraud, 2008; Nishino et al., 2011). Multi-point measurements at the magnetopause are therefore crucial for further investigation of these effects, since multiple MR sites may exist (Dunlop et al., 2009; Pu et al., 2007) and/or different transport mechanisms may occur simultaneously (Taylor et al., 2007).

Investigations into the operation of MR have searched for both direct sampling of the magnetic X-line structure, with its associated ion and electron diffusion regions, system of Hall currents and null (zero) field values along the merging line (see Drake et al., 1997; Fujimoto et al., 1997; Mozer et al., 2002; Oiereset et al., 2001; Vaivads et al., 2004), and indirect monitoring of the occurrence and motion of bundles of reconnected flux (flux tubes, Russell and Elphic, 1978; Haerendel et al., 1978), which move in predictable ways from an established X-line during periods of ongoing or intermittent reconnection (e.g. Wild et al., 2007; Dunlop et al., 2005). The local magnetic shear angle varies with location on the dayside magnetopause, however, so that the actual occurrence of MR tends to be patchy, or sporadic, across the magnetopause (Paschmann et al., 1979). Current debate distinguishes between those locations where this shear angle is close to anti-parallel (anti-parallel reconnection, e.g. Crooker, 1979; Crooker et al., 1998) and those which occur for a range of shear angles across the magnetopause (component reconnection, e.g. Sonnerup, 1970; Cowley, 1973, 1974a, b, 1976; Gonzalez and Mozer, 1974; Dorelli et al., 2004; Hesse and Schindler, 1988; Craig and Henton, 1995), since the role of a guide field in MR is important in control- ling the onset and rate of the reconnection process. Antiparallel sites depend on IMF orientation. They tend to occur either near the dawn or dusk flank magnetopause (under strongly tilted IMF $B_{\mathrm{y}}$ GSM), or at high latitudes near the polar cusps, or in the lobes (under northward IMF). Component driven locations are most probable along the low latitude line of maximum current for a given IMF tilt (the orientation of the low-latitude, magnetic merging line around the sub-solar point is predominantly controlled by the IMF clock angle).

Nevertheless, simultaneous measurements across the dayside magnetopause, which would confirm actual onset locations of MR across the magnetopause surface, have been sparse until recently. Early experimental evidence in fact suggested a predominantly component driven occurrence of MR on the dayside magnetopause, dominated by a (near subsolar) low latitude reconnection line, during both southward or strongly East-West directions of the IMF (Paschmann, 2008); anti-parallel sites being typically limited to the lobe regions, tailward of the Earth's magnetospheric cusps, under conditions of northward IMF (see Twitty et al., 2004; Phan et al., 2007). More recent findings (e.g. Trattner et al., 2007; Pu et al., 2007; Dunlop et al., 2009), however, have provided evidence for the occurrence of both component driven, low-latitude merging and anti-parallel, high-latitude sites during strong IMF $B_{\mathrm{y}}$. Furthermore, a recent eventbased global MHD simulation has predicted MR occurring simultaneously at low and high latitudes at large IMF $B_{\mathrm{y}}$ (Berchem et al., 2008). It is important, therefore, to gather further, direct evidence of MR activity at many widely distributed locations on the magnetopause, particularly under conditions of strong east-west IMF, in order to clarify such behaviour.

The use of distributed spacecraft measurements in this context has recently been enhanced through the coordinated measurements of the Cluster, Double Star (DSP), and THEMIS spacecraft (Escoubet et al., 2001; Liu et al., 2005; Angelopolous, 2008). Previous multi-scale conjunctions between the Cluster and DSP TC-1 satellites have been analysed by Dunlop et al. (2005) and Wang et al. (2007). The first paper confirmed that flux tubes observed at each spacecraft location originate from the same tilted X-line about the sub-solar MP, suggesting that component driven MR operates predominantly at the low latitude MP. North-south moving flux tubes are able to be simultaneously observed only because Cluster and TC-1 lie north and south of the X-line. In the second paper (Wang et al., 2007), the separation of TC-1 and Cluster along a flux tube confirms its tilt and motion as it is dragged around the dusk-side MP. Some statistical analysis of reconnection flows observed by Cluster and TC-1 under large IMF $B_{\mathrm{y}}$ have also been performed by $\mathrm{Pu}$ et al. (2005), implying that both component and anti-parallel MR sites may co-exist at the MP and that an extended, Sshaped X-line is probable (Trattner et al., 2007). The formation, extent and sub-structure of the low-latitude boundary layer and cusp and plasma transport during periods of 

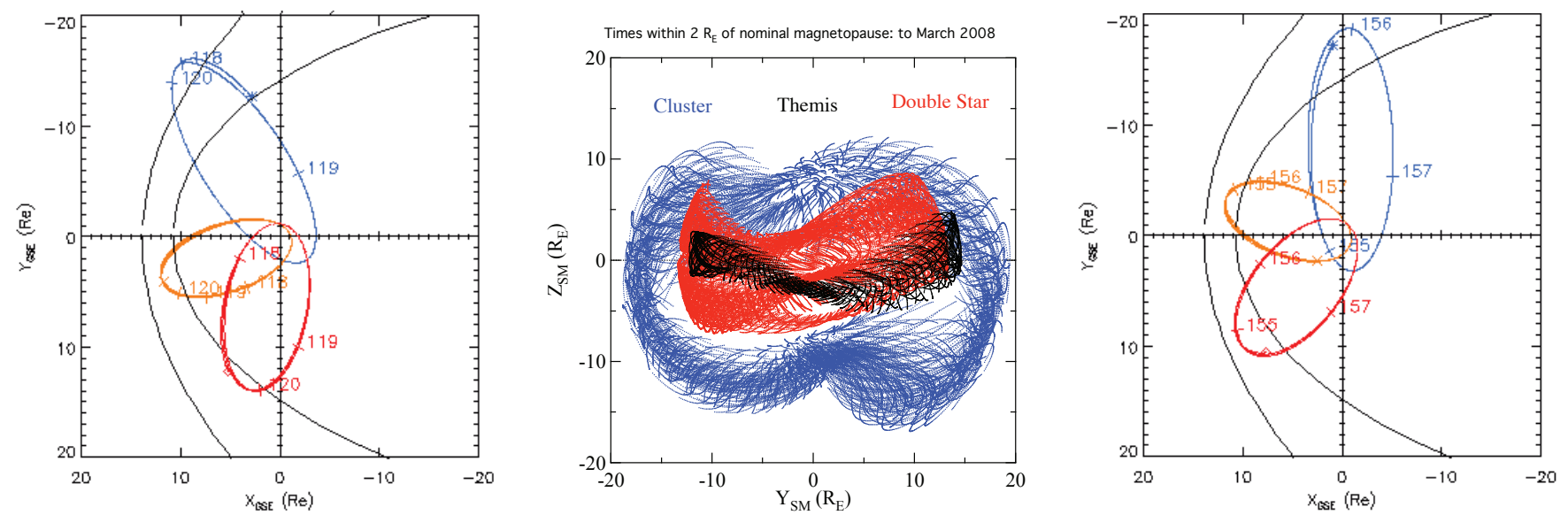

Fig. 1. Configuration of the Cluster, TC-1 and THEMIS spacecraft during the epoch April-August 2007. The left hand panel shows the early orientation with the five THEMIS spacecraft on the dusk-side magnetosphere (red orbits), TC-1 near noon (orange orbit) and the four Cluster spacecraft on the dawn-side magnetosphere (blue orbits). One obit track is drawn in the cases of Cluster and THEMIS. The right hand panel shows the orientation at the end of the phase and the centre panel shows the overall coverage across the magnetopause, as seen from the sun.

northward IMF have been investigated with other spacecraft conjunctions and also using ground radar data (Dunlop et al., 2008; Bogdanova et al., 2008). Flux tube structure has also been studied by Owen et al. (2008) and Hasegawa et al. (2004b).

All these studies can be extended using additional spacecraft and the launch of the THEMIS spacecraft provided an opportunity to use an extended set of distributed, measurements on multiple spatial scales. For example, during April to August 2007, and as shown in Fig. 1, the coordinated operation of the four Cluster spacecraft, the Double Star TC-1 and the five THEMIS spacecraft together produced a unique combination of $10 \mathrm{in}$-situ satellite measurements at the magnetopause, producing a series of simultaneous conjunctions which allowed multi-scale exploration of the conjugate response of the dayside MP across a wide range of local time. Other spacecraft (such as Geotail, Polar, and TC-2) are also available for certain events. This type of configuration allows us to study the spatial distribution and evolution of MR (on both dawn-dusk flanks simultaneously) and the inner structure of the reconnection layer, particularly under conditions of strong IMF $B_{\mathrm{y}}$. In the sections below, we first outline these measurements and the experimental configuration, concentrating on a particular close conjunction and summarising some related additional events. The first event uses these widely spaced measurements to show unambiguous evidence for an extended reconnection line across the whole of the dayside magnetopause; along the length of which (at least) patchy regions of MR occur. Complementary evidence for locally generated MR regions, operating both near the flank magnetopause and from a tilted, sub-solar Xline, under strong $B_{\mathrm{y}}$ is provided by the other conjunctions.

\section{Measurements}

\subsection{Multi-point dataset}

The in situ multi-point measurements used here are taken from the plasma and field instruments onboard the fourspacecraft ESA Cluster mission (Escoubet et al., 2001), TC-1 (one of the two spacecraft on the Chinese Double Star mission (Liu et al., 2005) and from the five THEMIS spacecraft (Angelopolous, 2008) in their "string of pearls" configuration. The four Cluster and TC- 1 spacecraft carry almost identical Flux Gate Magnetometers (for descriptions of each FGM, see Balogh et al., 2001, and Carr et al., 2005), which provide calibrated data to an accuracy of less than $0.1 \mathrm{nT}$, and at $22.4 \mathrm{~Hz}$, and similar electron and proton mass spectrometers on each spacecraft (Johnstone et al., 1997; Fazakerley et al., 2005; Rème et al., 2001, 2005), capable of measuring the thermal plasma populations in the overall energy range $3 \mathrm{eV}-$ $40 \mathrm{keV}$. The field and plasma instruments on THEMIS have a different design to those on Cluster and TC-1 (Auster et al., 2008; McFadden et al., 2008) but produce measurements in a similar energy range and resolution. Suitably time lagged solar wind magnetic field data from the ACE spacecraft (Smith et al., 1998) is also used.

\subsection{June 2007}

Figure 2a shows one of a series of conjunctions of these ten spacecraft, which were all situated south of the equator and distributed around the magnetopause in local time and where the overall transition is from the magnetosphere to the magnetosheath. The four Cluster spacecraft were in a tetrahedral configuration at $\sim 10000 \mathrm{~km}$ separations and were travelling outbound on the near equatorial dawn flank (inbound Cluster magnetopause crossings are at high southerly latitudes). 
THEMIS, Cluster \&TC-1 Orbit 2007 Jun 14
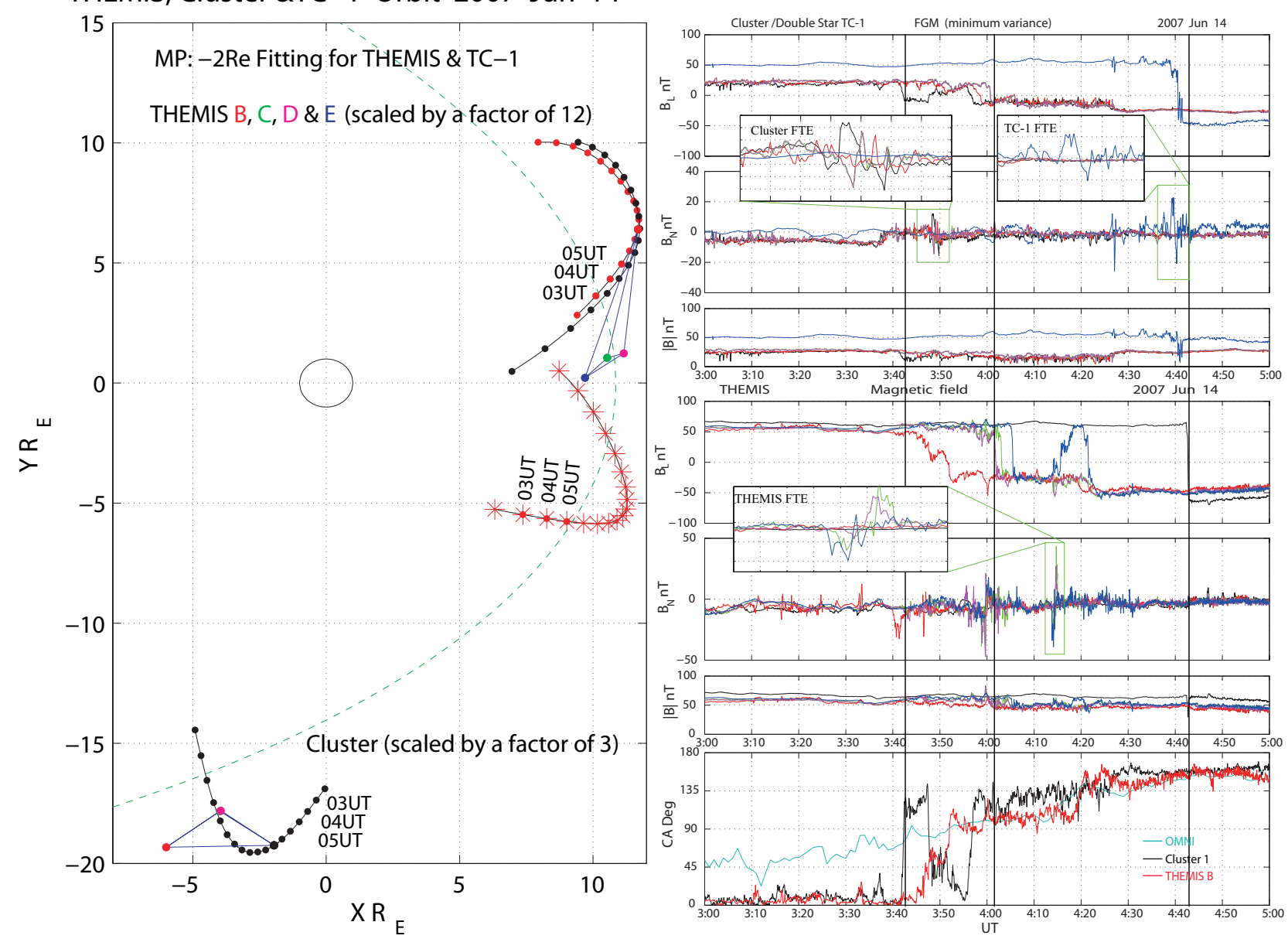

Fig. 2. A coordinated magnetopause encounter of the 5-THEMIS, TC1 and 4-Cluster spacecraft. (a) Shows the spacecraft locations in the equatorial plane (with the 4-Cluster and THEMIS B-E spacecraft configurations indicated), where the time interval of the data plot in (b) is indicated on the orbit segments (drawn for longer time intervals). The dashed line is a cut through a model magnetopause (Sibeck et al. 1991), as indicated. (b) Shows multi-spacecraft, magnetic field data for all 10 spacecraft in boundary normal co-ordinates (where $L$ is aligned to the background field tangential to the magnetopause and $n$ is the magnetopause normal). Only the field magnitude and the $N$ and $L$ components are shown here. The colours used to indicate each spacecraft are: black, red, green, and magneta, for Cluster $1-4$ and THEMIS A-D, and blue for both TC-1 and THEMIS-E. The lower panel on the right hand plot shows the clock angle (the angle of the IMF in the Y,Z plane, measured from Z), calculated for Cluster 1 (in the magnetosheath continually after 04:00 UT), THEMIS B (in the magnetosheath after 03:50 UT) and the OMNI data. The insets show zoomed time intervals for the selected FTEs to better show the signatures in these cases.

The five THEMIS spacecraft were outbound in a near equatorial $4+1$ configuration at $\sim 14: 00 \mathrm{LT}$ and the TC-1 spacecraft was also outbound at low southerly latitudes, at $\sim 10: 00 \mathrm{LT}$. Figure 2 shows a projection in the GSE X,Y plane so that the local time separation between the spacecraft can be seen. The spacecraft configurations for THEMIS and Cluster have been enlarged by the factors indicated for clarity and we have followed the Cluster sequence colours for THEMIS (A-black, B-red, C-Green, D-magenta, E-Blue). The plot also shows a fitted, model magnetopause at the time of the magnetopause crossings (taking a Pram $=2 \mathrm{nPa}$ and southward IMF).
During the traversal, the IMF turns southward from an initially strong $+B_{\mathrm{y}}$, while the solar wind ram pressure slowly increases (see Fig. 2b). These conditions produce a series of magnetopause crossings at all spacecraft within a period of about $40 \mathrm{~min}$ (see Fig. 2b, where the first and last crossings are indicated, together with the main sequence of Cluster and THEMIS crossings around 04:00 UT). The cut in the XY plane through the fitted magnetopause is at $Z_{\mathrm{GSE}} \sim-2 R_{\mathrm{E}}$ (the mean position of the spacecraft) and fits the relative positions of THEMIS and TC-1 at the time of their MP crossings very well. The Cluster spacecraft appear to actually cross late into the magnetosheath, implying a tilting or flaring of the 
Table 1. The direction of motion $(d)$ and speed $\left(V_{d}\right)$ of the FTE signatures, using de Hoffmann-Teller analysis, on Cluster and THEMIS where available, seen during the 14 June 2007 event. Here the IMF was initially in $+B_{\mathrm{y}}$, and turns into $-B_{\mathrm{z}}$ (after 03:50), the solar wind ram pressure was steadily increasing.

\begin{tabular}{lccr}
\hline SC & FTEs & $d(\mathrm{deHT})$ & $V_{d}\left(\mathrm{~km} \mathrm{~s}^{-1}\right)$ \\
\hline TH_A & $04: 46: 36$ & $0.18-0.020 .98$ & 83.67 \\
TH_B & $04: 00: 09$ & $-0.380 .62-0.69$ & 71.77 \\
& $03: 59: 27$ & $-0.92-0.08-0.38$ & 62.79 \\
TH_C & $04: 14: 43$ & -0.350 .850 .41 & 61.58 \\
& $03: 59: 50$ & $-0.520 .46-0.72$ & 90.74 \\
TH_D & $04: 14: 28$ & -0.390 .920 .01 & 93.98 \\
& $03: 48: 51$ & $-0.41-0.10-0.91$ & 130.47 \\
CL_3 & $03: 52: 13$ & $-0.59-0.28-0.76$ & 134.30 \\
& $04: 01: 53$ & $-0.56-0.30-0.78$ & 161.18 \\
& $03: 48: 52$ & $-0.61-0.360 .71$ & 165.44 \\
CL_4 & $03: 52: 14$ & $-0.88-0.47-0.06$ & 309.20 \\
& $04: 01: 53$ & $-0.89-0.45-0.13$ & 268.44 \\
\hline
\end{tabular}

magnetopause surface for the initially strong $B_{\mathrm{y}}$ conditions (the predicted position of Cluster is deeper into the magnetosheath at the time of the crossings). This flaring is supported by the results of boundary normal analysis (using both minimum variance (MVA) and de Hoffmann-Teller analysis where plasma data is available) at the crossings. Magnetopause velocities are high at THEMIS, ranging from $\sim 100$ $200 \mathrm{~km} \mathrm{~s}^{-1}$, and low at Cluster $\sim 30 \mathrm{~km} \mathrm{~s}^{-1}$, which are consistent with the tailward orientation of Cluster. At this location the magnetopause has a tangential orientation with respect to the sun-Earth line so that the effective (projected) inwards motion is lower than at the sub-solar position.

Figure $2 b$ shows the multi-spacecraft magnetic field data from all 10 spacecraft during the exits into the magnetosheath (here Cluster and TC-1 have been combined to form a five spacecraft plot, with TC-1 corresponding to the blue trace, and therefore match the five THEMIS colours). These data have been transformed into individual MVA coordinates for each spacecraft (labelled $N, M, L$, after Russell and Elphic, 1978, where $N$ is the magnetopause normal, $L$ is in the $\left(Z_{\mathrm{GSM}}, N\right)$ plane, $M$ completes a left-handed set and GSM is the geocentric solar magnetospheric coordinate system) to highlight both the magnetic shear in $B_{L}$ at the crossings and the existence of $B_{N}$ FTE signatures, assumed to be induced by passage of reconnected flux tubes. In fact the plasma data (not shown here) indicate that the Cluster spacecraft lie mainly in the magnetosheath, although spacecraft 1 shows clear re-entries into the magnetosphere around 03:45 UT, just before the THEMIS crossings begin. These exits are revealed also in the lower panel of Fig. 2b, which shows the clock angles. Cluster 1 picks up a local magnetosheath orientation between 03:40 and 03:50 UT, and then follows the OMNI estimate of solar wind clock angle, along with THEMIS B, after about 03:55 UT. The southward turning after 04:00 UT is also apparent at all the locations. The Cluster location is in fact consistent with anti-parallel flank magnetospheric and magnetosheath fields. Immediately following the Cluster exits, the THEMIS spacecraft cross the magnetopause one by one, with THEMIS E (blue trace) showing a short magnetopause reversal. THEMIS B$\mathrm{E}$ are in a bunched configuration as shown in the left hand panel, but THEMIS A lags behind somewhat, producing a later crossing at 04:42 UT. This last crossing just happens to be simultaneous (within 1-2 min) with the crossing of TC1 (04:40 UT) and occurs after the main southward turning of the IMF. Throughout the interval, at all spacecraft, some FTE signatures (bipolar signatures in the $B_{n}$ component) can be seen. The polarity of these FTEs suggest that initially (during the strong IMF $B_{\mathrm{y}}$ ), most represent reconnected flux tubes which are moving eastward (and tailward) at the THEMIS BE spacecraft (which appear to cross the magnetopause south of the predicted sub-solar reconnection line), westward and northward at TC1 (which therefore crosses north of the implied reconnection line) and westward (and tailward) at the Cluster spacecraft.

Table 1 shows a summary of the analysis of FTE calculated motions (note that there is a lack of plasma ion data for C2, TC-1, and THEMIS E, and no clear FTEs were identified at $\mathrm{C} 1$ ), which confirm these directions. In particular, it is clear that at the THEMIS B-D spacecraft all FTEs, except one, show a southward component to their motion, as expected for a position just south of a sub-solar X-line (see discussion of Fig. 3a). The FTEs seen by the C3 spacecraft also have strong southward motion. At the $\mathrm{C} 4$ spacecraft, however, there are mixed (north and south) motions ( $d$ in Table 1) and we suggest this indicates local generation of flux tubes at the near anti-parallel flank location (we would expect reconnected flux tubes, arriving at Cluster from the sub-solar region, to have consistently strong, westward and northward motion as discussed later). During the time of the last crossing (04:42 UT), at THEMIS A and TC-1, the FTE motions are northward, consistent with the predicted turning of the Xline into the $Y_{\mathrm{GSE}}$ direction for the strongly southward IMF. This X-line orientation results in both THEMIS A as well as TC-1 lying just north, and very near, the X-line. We should note here, however, that although more detailed study of the plasma distributions (Dunlop et al., 2011) confirm that TC-1 indeed exits northward of the reconnection line, the bi-polar (FTE) signature at TC-1 is not clearly associated with a reconnected flux tube signature (and is omitted from Table 1).

This implied extent and orientation of the sub-solar merging line was identified further using model fits (Cooling et al., 2001; Trattner et al., 2007) for the ambient conditions, as shown in Fig. 3. The Cooling fit of the expected reconnection line, and map of predicted motions of reconnected flux tubes on the MP, in the left hand panel is for the IMF and solar wind conditions pertaining for the period just before the last crossings at TH-A and TC-1 (the final reconnection 

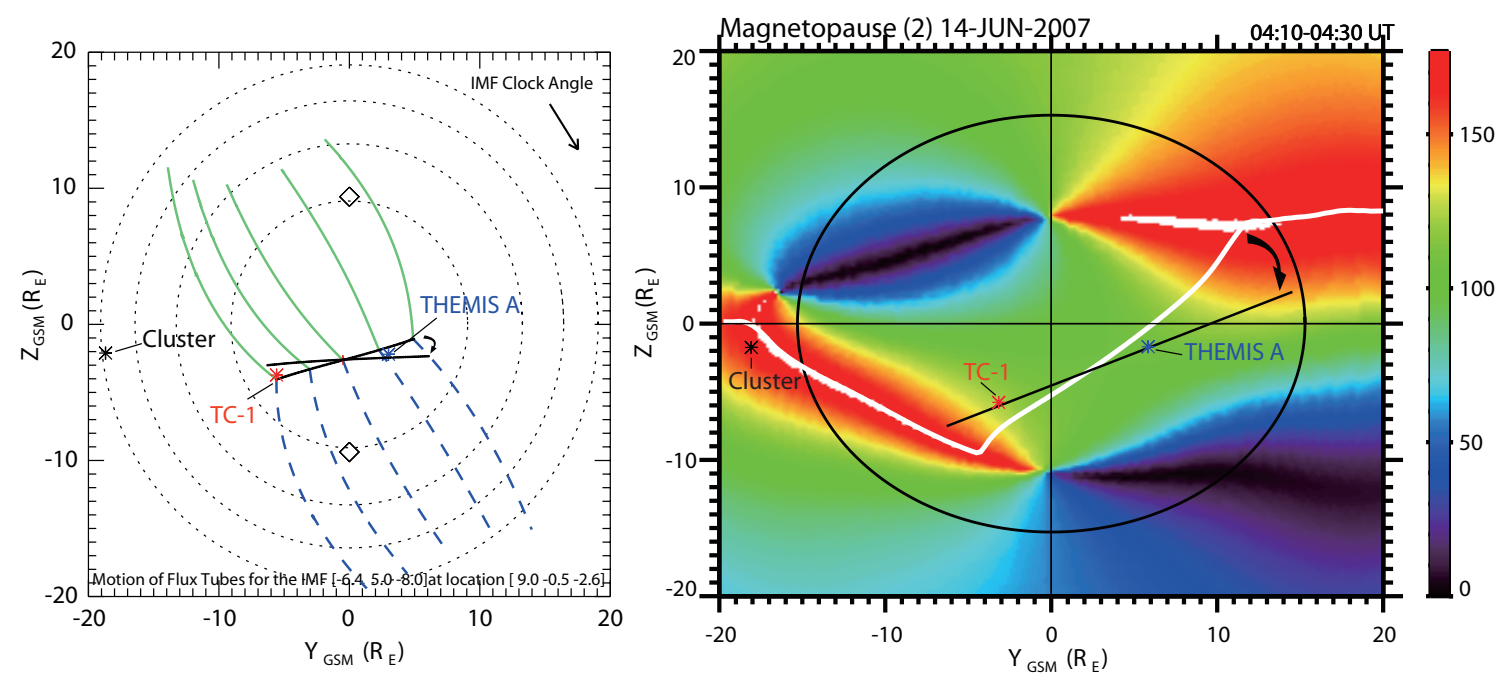

Fig. 3. The left panel shows the Cooling analysis of FTE motions from a predicted sub-solar X-line (taken as the position of maximum merging current at the MP), as seen from the Sun. The right panel shows the modelled, shear angles between the draped magnetosheath field and T96 Tsygenenko model. The white regions on the flanks are where the shear angle is close to anti-parallel and show possible reconnection locations extended into the flanks. The white line crossing the magnetopause is the most likely location of the reconnection line, as predicted by the Maximum Magnetic Shear Model (Trattner et al., 2007). Nearby spacecraft locations are shown as black crosses, and the black line is the final orientation of the fitted (Cooling) merging current line.

line orientation, for the most southward IMF orientation, is also drawn and this fitted Cooling orientation is drawn on the right hand panel also). The positions of Cluster, THEMIS and TC- 1 are indicated. It can be seen that, not only are the expected flux tube motions consistent with those obtained from the data analysis above, but also the expected X-line locus threads the TC- 1 and TH-A positions very closely. A rotation (or reforming) of the reconnection line, as the IMF turns progressively southward, results in the earlier THEMIS spacecraft crossing south of it (southward and duskward motion of reconnected flux tubes), while TH-A crosses north of it (northward moving flux tubes).

The right hand panel of Fig. 3 reflects this analysis, by showing the regions where the field was near anti-parallel using the same draped magnetosheath field from the Cooling model. The key additional information here, however, is that the implied extension of the probable locus of reconnection sites to those regions where the fields are close to anti-parallel, reveals that Cluster is situated close to these anti-parallel flank locations. It is hard to see how a simple extension of the sub-solar merging line would result in flux tubes passing by the Cluster locations. Furthermore, flux tubes which are locally generated near Cluster would tend to have southward velocity components, as observed in Table 1, whereas those generated by sub-solar reconnection would tend to have northward velocity components.

\subsection{Other close conjunctions}

Related events, involving multi-scale conjunctions of the spacecraft at the magnetopause, were observed on the 3 May, 28 June and 28 May 2007. The first two occurred during a period of active reconnection and all the events are shown in Figs. 4, and 5 in the same format as Fig. 1.

\subsubsection{The 3 May 2007 conjunction}

Figure 4 shows an event which has also been reported by Fear et al. (2009). The IMF in this case was directed strongly dawnward (see right hand side of Fig. 4a), rather than duskward, and then southward, in the case of the 14 June 2007 event, but it is nevertheless instructive to compare it here since this event also showed simultaneous FTEs, predominantly at both Cluster and THEMIS. The left hand panel of Fig. 4a shows the spacecraft locations, in the same projection as before, and the right hand panel summarises the magnetic field data and clock angle information. The clock angles show that THEMIS B picks up the local magnetosheath orientation as it exits after 12:00 UT and that the local magnetosheath orientation at Cluster 1 closely follows the OMNI estimate of IMF clock angle. The clock angles broadly agree at all locations in the magnetosheath or solar wind, and remain close to the $-B_{\mathrm{y}}$ orientation for most of the interval. Since Cluster is inbound at high southerly latitudes for this conjunction, three cuts through the MP have been indicated, corresponding to the heights (that is the $Z_{\mathrm{GSE}}$ position) of each spacecraft location. At $\sim 14: 00$ UT, THEMIS is outbound, but skimming the magnetopause (as shown) near 

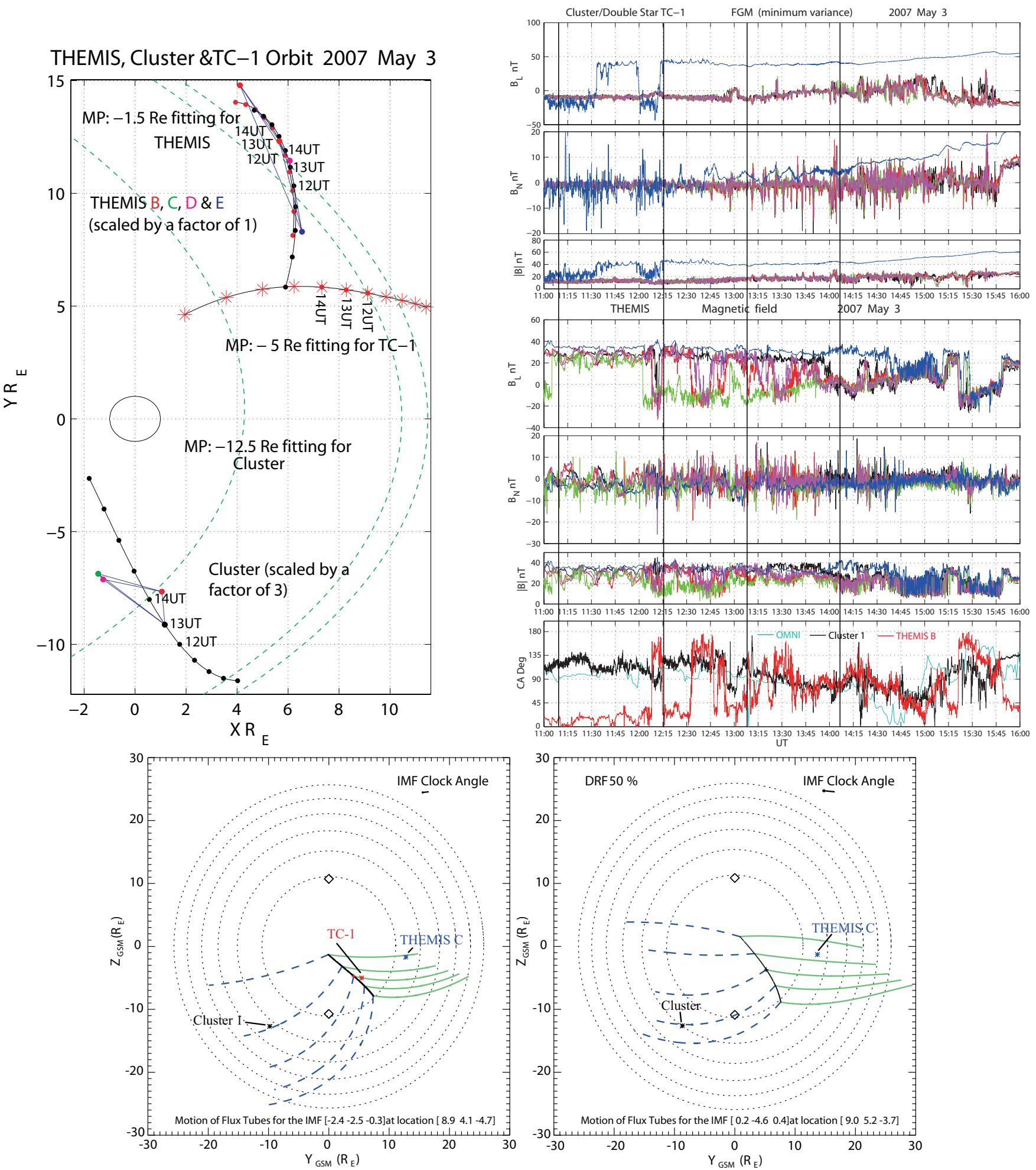

Fig. 4. A similar conjunction at the magnetopause, also reported by Fear et al. (2009), showing evidence of active reconnection in a similar format to Fig. 1: (a) summarises the ten spacecraft encounter which occurred under conditions of steady IMF $-B_{\mathrm{y}}$ and steady solar wind ram pressure. The lower panel on the right hand plot shows the clock angle, calculated for Cluster 1 (in the magnetosheath until 15:50 UT), THEMIS B (intermittently in the magnetosheath after 12:10 UT) and the OMNI data. (b) Shows the corresponding Cooling model fit and predicted FTE motions. Also marked by stars are the positions for the Cluster, THEMIS and TC-1 spacecraft, as indicated. The fit shown on the left corresponds to the IMF direction, predominantly prevailing for the overlapping time interval where all ten spacecraft see FTE signatures (10:30-12:00 UT), whereas the fit on the right corresponds to the IMF prevailing for the later interval (12:00-14:00 UT), where Cluster FTE signatures mainly overlap with THEMIS. 


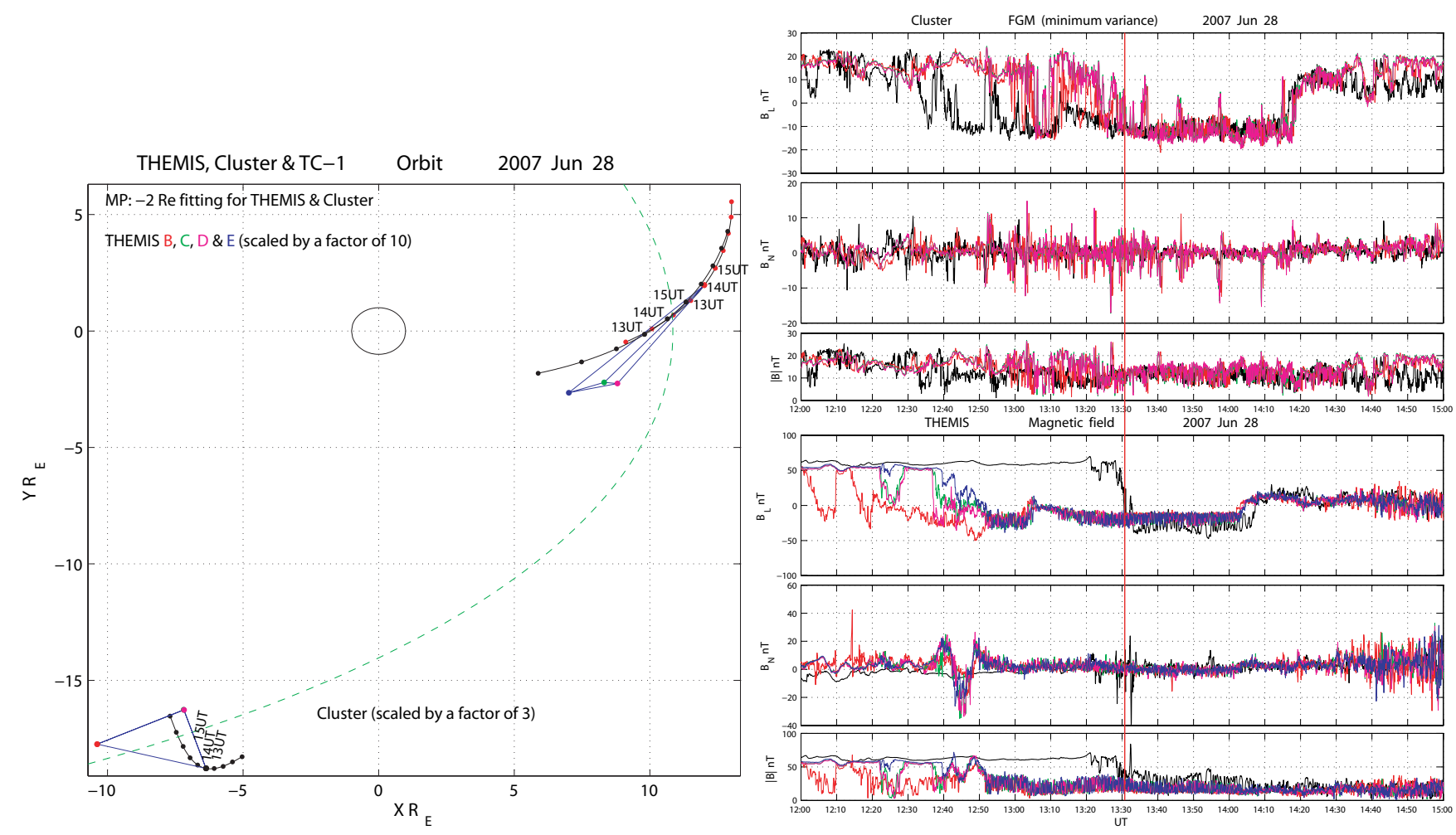

Fig. 5. A conjunction between the four Cluster and five THEMIS spacecraft, during an initially northward IMF, in a similar format to Fig. 1.

the equatorial plane and TC-1 is inbound, approximately $-5 R_{\mathrm{E}}$ south of the equator. The MP cuts suggest that all spacecraft are expected to be located near the magnetopause at this time, and at their various heights.

As indicated by the first two vertical black lines in the right hand panel of Fig. 4a, TC-1 crosses the MP first at $\sim 11: 30$ UT, then enters the magnetosphere at 12:15 UT, having encountered FTEs in the preceding interval. The other two vertical black lines mark the core overlap interval for signatures seen between Cluster and THEMIS. Cluster remains in the magnetosheath just upstream of the magnetopause until the later crossings of THEMIS at $\sim 15: 45$ UT. Throughout the time interval shown, the THEMIS spacecraft straddle the MP boundary, so that all THEMIS spacecraft at times cross the MP one by one. After 12:00 UT, for example, the outer spacecraft $(\mathrm{C})$ is in the magnetosheath and the inner spacecraft (A and E) are in the magnetosphere, with the other two moving repeatedly across the boundary. A standard MP surface (after Sibeck et al., 1991), fitted to solar wind pressure, matches these actual MP encounters well, implying that the magnetopause is well shaped and coherent for this encounter. In fact, the motion of all crossings of the magnetopause is slow and does not show large changes in motion.

All spacecraft also show FTE signatures for this event and those occurring for the main period of overlap with the other spacecraft are summarised in Table 2, together with their polarity as implied by their $B_{N}$ component. We list the FTE signatures corresponding to Cluster 3, THEMIS C and TC-1 only, for simplicity, in the table. The THEMIS spacecraft see FTEs through nearly the whole interval ( 10:30-14:30 UT), while TC-1 sees a number of FTEs before 12:00 UT and the Cluster spacecraft see FTEs after about 11:45 UT, as they approach the MP. A number of additional FTEs to those identified by Fear et al. (2009) are listed here for TC-1. In order to identify these FTEs observed by TC-1, we have carried out additional hodogram analysis of the magnetic field variation for all FTE-like signatures (not shown here). We find a clear indication of indentations as would be caused by a reconnected flux tube in both the L-M and L-N planes of the magnetic field. This analysis further suggests that the FTElike signatures result from flux tube passage. The Walén test for some of these intervals failed, perhaps due to the fact that the spacecraft did not cross the Alfvén wave, or rotational discontinuity (RD), during the FTE crossing (see Lockwood and Hapgood, 1998).

In fact, the FTE populations are approximately balanced for all spacecraft, given their respective locations: TC-1 sees FTE signatures until it begins to cross the MP into the magnetosphere (entering rather steeply as seen by the orbit path), while the THEMIS spacecraft remain skimming the magnetopause boundary throughout the interval and therefore continue to see FTEs (implying that reconnection is ongoing during this time). The Cluster spacecraft see increasing numbers of FTEs as they approach near enough to the 
southern magnetopause surface. The polarities of the FTEs on THEMIS and TC- 1 are consistent with the broad expectation from a strongly east-west direction of the IMF, as would arise from a common, strongly tilted, sub-solar X-line, as found by Fear et al. (2009) and as plotted in Fig. 4b. Here we show the Cooling model fits for two key times, as indicated, and the locations of the spacecraft are shown. The implied motion is confirmed by the predicted paths of the reconnected flux tubes resulting from each X-line orientation and is calculated in Table 2, for each FTE. The majority of FTEs observed at THEMIS are travelling most strongly eastward, so that the polarity test fails for a few of the FTE signatures seen, whereas the polarities calculated for TC-1, also eastward moving, are consistent with the consistently southward components obtained. Nevertheless, these motions agree reasonably well, for both spacecraft locations, with the implied directions predicted from the Cooling test, as shown in the left hand panel of Fig. 4b, calculated for the main overlap interval for the FTEs on THEMIS, Cluster and TC-1. We should note that he predicted speeds are rather higher that those found from the analysis (such discrepancy has been commented on before, however, by other authors, e.g. Wild et al., 2007).

These results place TC-1 just east of the merging current line predicted from the fitted Cooling model (see Fig. 4b). At this location, however, TC- 1 would be expected to see the largest number of flux tubes to be consistent with the number seen at the THEMIS spacecraft, even if the extent of the $\mathrm{X}$-line is limited, since THEMIS continues to see many FTE signatures over more than $2 \mathrm{~h}$, implying continuous reconnection activity throughout this time. In addition, the southward components of the motion of each signature at TC-1 are rather larger than expected from the directions predicted from the Cooling model. This argument leads us to a consideration of the FTEs seen at Cluster, and here we find that all calculated motions at Cluster have very strong southward components, even for the early FTE seen at 11:44 UT, and also are as populous as those seen at THEMIS. The right hand panel of Fig. 4b shows the Cooling fit for the later interval, corresponding to the main overlap with THEMIS and Cluster. The predicted motions at Cluster do not have large southward components and are directed predominantly westward. The calculated motions at Cluster show only small westward components, implying that the majority of the FTEs seen at Cluster are not arising from the subsolar region. It is therefore possible that at Cluster and THEMIS, or at least at the Cluster spacecraft, locally generated flux tubes are being seen at their flank locations, as suggested for the 14 June event. We cannot rule out, however, that, despite the constant solar wind conditions, which are maintained throughout this interval, the reconnection rate changes over the long period of time of these observations.
Table 2. The direction of motion $(d)$ and speed $\left(V_{d}\right)$ of the FTE signatures, using de Hoffmann-Teller analysis, seen during the 3 May 2007 event shown for (a) Cluster-3 and (b) THEMIS-C. Here the IMF was directed into $-B_{\mathrm{y}}$.

\begin{tabular}{cccr}
\hline UT (C 3$)$ & Polarity & $d(\mathrm{deHT})$ & $V_{d}\left(\mathrm{~km} \mathrm{~s}^{-1}\right)$ \\
\hline $11: 44: 43$ & $-/+$ & $-0.44-0.20-0.88$ & 171.82 \\
$12: 46: 23$ & $-/+$ & $-0.46-0.26-0.85$ & 190.91 \\
$13: 11: 54$ & $-/+$ & $-0.60-0.19-0.77$ & 243.53 \\
$13: 18: 00$ & $-/+$ & $-0.65-0.18-0.74$ & 251.81 \\
$13: 26: 09$ & $-/+$ & $-0.66-0.39-0.64$ & 266.89 \\
$13: 39: 54$ & $-/+$ & $-0.66-0.23-0.72$ & 241.78 \\
$13: 43: 19$ & $-/+$ & $-0.64-0.21-0.74$ & 251.28 \\
$13: 50: 10$ & $-/+$ & $-0.65-0.17-0.74$ & 235.84 \\
$14: 04: 32$ & $-/+$ & $-0.51-0.25-0.82$ & 220.82 \\
$14: 17: 36$ & $-/+$ & $-0.55-0.20-0.81$ & 228.10 \\
\hline UT TH-C & Polarity & $d(\mathrm{deHT})$ & $V_{d}\left(\mathrm{~km} \mathrm{~s}^{-1}\right)$ \\
\hline $10: 28: 04$ & $+/-$ & -0.700 .710 .06 & 131.25 \\
$10: 45: 32$ & $+/-$ & $-0.250 .18-0.95$ & 271.62 \\
$11: 09: 30$ & $+/-$ & -0.240 .490 .84 & 160.73 \\
$11: 18: 35$ & $+/-$ & -0.110 .260 .96 & 183.54 \\
$11: 22: 44$ & $+/-$ & $-0.670 .73-0.12$ & 221.43 \\
$11: 36: 44$ & $+/-$ & $-0.670 .68-0.31$ & 158.60 \\
$11: 39: 38$ & $-/+$ & -0.540 .600 .59 & 132.69 \\
$11: 45: 13$ & $-/+$ & -0.370 .930 .06 & 55.95 \\
$11: 51: 23$ & $+/-$ & $-0.690 .73-0.05$ & 163.75 \\
$12: 15: 02$ & $+/-$ & $-0.660 .73-0.16$ & 176.74 \\
$12: 24: 25$ & $+/-$ & $-0.680 .71-0.15$ & 207.61 \\
$12: 37: 20$ & $+/-$ & $-0.710 .70-0.12$ & 183.07 \\
$12: 42: 11$ & $+/-$ & $-0.690 .70-0.18$ & 175.23 \\
$12: 46: 01$ & $-/+$ & $-0.690 .69-0.21$ & 186.23 \\
$12: 57: 15$ & $+/-$ & -0.650 .760 .05 & 210.43 \\
$13: 00: 00$ & $+/-$ & $-0.700 .71-0.03$ & 211.83 \\
$13: 01: 39$ & $+/-$ & $-0.710 .69-0.14$ & 234.71 \\
$13: 06: 30$ & $+/-$ & $-0.720 .69-0.11$ & 238.83 \\
$13: 11: 13$ & $+/-$ & $-0.710 .70-0.11$ & 206.52 \\
\hline TC-1 & Polarity & $d(\mathrm{deHT})$ & $V_{d}\left(\mathrm{~km} \mathrm{~s}^{-1}\right)$ \\
\hline $10: 41: 50$ & $-/+$ & $-0.490 .65-0.58$ & 126.70 \\
$11: 12: 59$ & $-/+$ & $-0.430 .83-0.35$ & 145.78 \\
$11: 15: 52$ & $-/+$ & $-0.590 .69-0.42$ & 134.49 \\
$11: 29: 54$ & $-/+$ & $-0.390 .88-0.27$ & 148.77 \\
$11: 36: 31$ & $-/+$ & $-0.510 .85-0.10$ & 120.88 \\
$11: 40: 33$ & $-/+$ & $-0.350 .90-0.28$ & 121.92 \\
$12: 00: 42$ & $-/+$ & $-0.450 .85-0.27$ & 183.57 \\
$12: 01: 52$ & $-/+$ & $-0.450 .86-0.24$ & 165.29 \\
$12: 03: 49$ & $-/+$ & $-0.570 .32-0.76$ & 126.21 \\
\hline & & &
\end{tabular}

\subsubsection{The 28 June 2007 conjunction}

Figure 5 shows a conjunction between the THEMIS and Cluster spacecraft while TC-1 remained in the magnetosphere. Both Cluster and THEMIS are near equatorial. The event occurred while the IMF was initially northward, but 
turned into strong $-B_{\mathrm{y}}$ at about the time of the TH-A crossing (vertical red line). The solar wind pressure was steady during the interval. The THEMIS spacecraft are outbound so that the THEMIS B-E spacecraft exit during northward IMF, while TH-A exits during strong $B_{\mathrm{y}}$. At the same time the Cluster spacecraft are near apogee far on the dawn flank, just upstream of the MP. The THEMIS B-E spacecraft appear to see no reconnection activity, and in fact see evidence of a PDL and a mirror mode band in the magnetosheath. This is evident in $|B|$ and the $B_{L}$ component at about 13:05 UT in the lower right hand plot of Fig. 5, which shows an almost constant lower level for the band of dropouts in $|B|$. At the time of the TH-A crossing, the character changes, so that the PDL and mirror band appear to be absent, and one large FTE signature (at 13:32 UT), together with two smaller amplitude signatures (at 13:28 and 13:30 UT) are observed. These FTEs have duskward and northward motion, as expected for this IMF and the position of TH-A. This change in character between the exits of the THEMIS spacecraft, suggests a rapid response of the conditions at the magnetopause to the sudden change in IMF orientation, within a few hours of noon.

Despite the lack of reconnection signatures at THEMIS B$\mathrm{E}$, while the IMF was predominantly northward, the Cluster spacecraft observe a number of FTE signatures throughout the period 12:40-14:20 UT at their location on the dawn flank. Although not shown here, all the Cluster FTEs have been analysed and are are moving tailward around the flank, so that we cannot rule out the possibility that after 13:30 UT Cluster began to see at least some FTEs arising from the sub-solar region. The majority of these FTEs, however, have strong southward motion both before and after 13:30 UT. We suggest that this again implies there is local generation of reconnected flux tubes at this flank location, since there is no evidence of reconnection (at THEMIS) in the sub-solar region before 13:30 UT.

\section{Discussion}

The analysis of the 14 June 2007 event suggests that the extended locus of possible reconnection sites (as shown in Fig. 3b) follows closely the three LT locations of the spacecraft for the ambient conditions of the event and supports the interpretation that these near simultaneous encounters are consistent with both a tilted X-line in the dayside LLBL and anti-parallel sites extending into flank locations, with near simultaneous activity all along the region. Based on the paradigm of component driven MR, this configuration is consistent with the initial $B_{\mathrm{y}}$ orientation of the IMF and has been predicted by other authors as well as being sampled at one or another site using limited spacecraft coverage (for example, see the discussion in Phan et al., 2004; Retino et al., 2005, and as highlighted in the Introduction here). Nevertheless, we believe this is the first time the occurrence of MR, operating at the same time all across these locations has been shown and is a direct result of the special extended configuration of spacecraft realised by the combined THEMIS, Cluster and DSP missions.

In the context of component reconnection, the turning of the IMF from an east-west orientation, to southward, produces a tilted, but possibly reforming (or rotating) sub-solar X-line (modelled in Fig. 3a), so that the THEMIS B-E spacecraft pass south of the tilted merging line, while TH-A passes north of it. For the last crossing, this merging line threads the TC-1 and TH-A positions so that these spacecraft, separated by $\sim 10 R_{\mathrm{E}}$ either side of noon, each cross the MP simultaneously very close to reconnection sites (Dunlop et al., 2011). The results presented above show that the observed FTEs are consistent with this scenario (northward FTEs at TH-A and TC-1 and southward FTEs at THEMIS B-E). Furthermore, the motions of the few observed flux tubes seen at Cluster were shown to be unlikely to originate from these sub-solar sites. The Cluster FTEs have both mixed and southward motions (Table 1), which are more consistent with local generation at the (anti-parallel) flank location. In fact, the highest and inner most located spacecraft, Cluster 4, expected to be most likely to lie above the local reconnection line, shows one northward FTE, whereas Cluster 3 does not. Similarly, although one FTE at TH-C has a northward component, it is seen later, at 04:14 UT, following the southward rotation of the IMF. Thus, the motions of FTEs are broadly consistent not only with the large scale pattern depicted by the Cooling model, but also with local generation at high probability (anti-parallel) sites on the flanks (for this IMF orientation). Although the evidence is also consistent with the occurrence of patches of MR activity, which then generate the observed populations of reconnected flux tubes, this activity is seen to be localised to the extended merging line, rather than from random sites (as suggested by Nishida, 1989), so that the large scale configuration across the magnetopause is maintained.

The reconnection signatures tracked here are also being investigated with a global MHD model for the observed upstream conditions (see Berchem et al., 2008), which shows evidence of possible reconnection activity present at the THEMIS, TC- 1 and Cluster locations, broadly in agreement with the in situ analysis. Future work will analyse further the plasma distributions for these conjunctions. For the 14 June 2007, in particular, the THEMIS data show highly complex signatures in the $B_{N}$ components. These have been analysed, together with the bulk plasma flows where available, by Hasagawa et al. (2010) and suggest the presence of multiple or reforming X-line structure at this time.

This interpretation of locally generated reconnected flux tubes (away from the sub-solar region) is also suggested by the analysis of the 3 May 2007 event, where large numbers of FTEs are seen at all ten spacecraft, whereas slightly fewer than expected are seen at TC-1. The IMF orientation, predominantly in $B_{\mathrm{y}}$, does not suggest strongly antiparallel locations in this case. It is possible, however, that 
the TC-1 spacecraft enters deeply into the magnetosphere too soon for many FTEs to be sampled (see the orbit locations in Fig. 4a): TC-1 lies in the magnetosheath, and at the MP boundary, only before 12:00 UT. Although the Cooling model, shown in Fig. 6b, confirms that the direction and motion of the observed FTE at TC-1 and THEMIS are broadly consistent with their locations relative to the sub-solar merging line, TC-1 has stronger southward motions than expected for a Cooling fit which incorporates the THEMIS observations also. Furthermore, it should also be noted here that in the study of Fear et al. (2009), the lack of FTEs seen at TC1 was interpreted as a limit on the extent of activity along the tilted merging line. Placing such a limit on the Cooling model fit (for example, by raising or shortening the assumed extent of the subsolar X-line, as in Fig. 4), can result in TC-1 lying outside the locus of possible flux tube tracks, while Cluster and THEMIS lie on expected flux tube paths. Nevertheless, the Cooling model fit, modified for the IMF orientation (slightly northward and in $B_{\mathrm{y}}$ ) corresponding to the main over lapping interval $\sim 13: 00-14: 00$ UT (shown in the right hand panel of Fig. 4b), results in expected flux tube tracks that also place Cluster at the edge of the field of expected flux tubes (note that Cluster lies at southerly latitudes in this event) and imply strongly westward motion at Cluster. While the direction, and motion, of the FTEs seen at THEMIS are broadly consistent with the modelled motions shown in Fig. 4b (i.e. strongly duskwards), those seen at Cluster all have stronger southward motion than expected for a purely sub-solar X-line. We conclude that this event suggests that both local flank and sub-solar sources are probable to explain the signatures seen at all spacecraft.

The third event 28 June 2007, shown in Fig. 5a, also reveals a large number of FTEs, seen at Cluster's flank location, while the IMF had a northward and dawnward orientation. In this case, however, Cluster is again close to equatorial and there remains a high local shear between the magnetosheath and magnetospheric fields (see the relative orientations of $B_{L}$ as each Cluster spacecraft straddle the MP boundary). At the same time, THEMIS B-D, near the sub-solar point, do not detect any FTE signatures. By the time of the THEMIS A crossing, after the IMF rotation from northward to a strong $B_{\mathrm{y}}$ orientation, a large northward and duskward moving FTE observed, which is consistent with its position relative to a sub-solar merging line. It is probable, therefore, that the sites of active reconnection regions, operating around the MP in this case, re-distribute themselves rapidly following this turning of the IMF. In fact, FTE signatures are seen throughout the whole interval shown in Fig. 5a, at Cluster's flank location, and are assumed, at least initially, to be sourced from local flank reconnection sites, whereas sub-solar reconnection appears to switch on as the IMF rotates into its southward orientation. This behaviour is also consistent with the inherently "component" driven scenario, irrespective of the guide field conditions for IMF orientation.
We also note in passing that the MP fits underlying the investigation of reconnection activity have also provided some case-based confirmation of the global response of the magnetopause. Many statistical studies have been carried out to determine the global shape of the MP under differing external pressure and IMF (Sibeck et al., 1991; Shue et al., 1998), however there have been few distributed, multi-spacecraft encounters such as we have here to check global shape for particular events. We have found that, although in a mean sense the surface model used here (Sibeck et al., 1991) provided a good fit to the actual encounters, particularly for the THEMIS and TC-1 near equatorial locations either side of noon, clearly large deviations can occur at the flank position of the Cluster spacecraft particularly under the predominantly strong $B_{\mathrm{y}}$ orientation of the IMF. These statements are justified by the MP fits shown in Figs. 2a, 4a, and 5.

\section{Conclusions}

Reconnection signatures have been tracked across a wide range of local times, using conjunctions of 10 spacecraft around the magnetopause and predictions from the Cooling model, which broadly confirm a number of features of the occurrence and motion of reconnected flux tubes and hence, by implication, confirms the simultaneous operation of MR across the MP, which is primarily localised to the extended merging line, not only along the sub-solar merging line but simultaneously at other favourable locations across the MP. For example, the conjunctions discussed here have provided:

1. Confirmation of east-west opposite moving FTEs, consistent with a tilted X-line following the IMF orientation (typically under strong IMF $B_{\mathrm{y}}$ ).

2. Confirmation that there is simultaneous generation of reconnected flux tubes far from local noon, arising from anti-parallel flank sites for at least one conjunction, since there is often a high FTE occurrence at Cluster $\&$ THEMIS positions.

3. Confirmation that there can be a rapid re-distribution of MR sites, resulting from a change in IMF orientation from northward IMF to strong $B_{\mathrm{y}}$.

Although the results shown here are consistent with the formation of patches of reconnection which then generate the observed populations of reconnected flux tubes, this activity (although, by implication, variable) therefore maintains a large scale configuration across the magnetopause. The occurrence of MR broadly depends on IMF orientation, and therefore inherently follows a "component" driven scenario irrespective of the guide field conditions. This result is in agreement with previous observations (Trattner et al., 2004; Retino et al., 2005) and with numerical simulations (Swisdak et al., 2005), but has been shown here for the first time 
to occur simultaneously at widely separated sites along the extended merging line.

In addition, the particular distribution of spacecraft around the MP has provided good confirmation of the MP morphology for individual events and has been able to resolve particular global response to a number of dynamic conditions. For example, simultaneous MP crossings on the dawn-side and dusk-side show a skewed MP shape on the flank location, under conditions of strong $B_{\mathrm{y}}$ and decelerating MP compression can be confirmed with changing solar wind dynamic pressure.

Acknowledgements. This work is partly supported by Chinese Academy of Sciences (CAS) visiting Professorship for senior international scientists grant no. 2009S1-54 and the Specialized Research Fund for State Key Laboratories of the CAS and through a working group, sponsored by ISSI, Berne. Q.-H. Zhang was supported by an STFC IHR grant and is partly supported by Ocean Public Welfare Scientific Research Project, State Oceanic Administration People's Republic of China (No. 201005017). JPE holds an STFC Advanced Fellowship at Imperial College London.

Guest Editor A. Masson thanks A. R. Retinò and another anonymous referee for their help in evaluating this paper.

\section{References}

Angelopolous, V.: The THEMIS mission, Space Sci. Rev., 141, 534, doi:10.1007/s11214-008-9336-1, 2008.

Auster, H. U., Glassmeier, K. H., Magnes, W., Aydogar, O., Baumjohann, W., Constantinescu, D., Fischer, D., Fornacon, K. H., Georgescu, E., and Harvey, P.: The THEMIS fluxgate magnetometer, Space Sci. Rev., 141, 235-264, 2008.

Balogh, A., Carr, C. M., Acuña, M. H., Dunlop, M. W., Beek, T. J., Brown, P., Fornacon, K.-H., Georgescu, E., Glassmeier, K.H., Harris, J., Musmann, G., Oddy, T., and Schwingenschuh, K.: The Cluster Magnetic Field Investigation: overview of in-flight performance and initial results, Ann. Geophys., 19, 1207-1217, doi:10.5194/angeo-19-1207-2001, 2001.

Berchem, J., Marchaudon, A., Dunlop, M., Escoubet, C. P., Bosqued, J. M., Reme, H., Dandouras, I., Balogh, A., Lucek, E., Carr, C., and $\mathrm{Pu}, \mathrm{Z}$.: Reconnection at the dayside magnetopause: Comparisons of global MHD simulation results with Cluster and Double Star observations, J. Geophys. Res., 113, A07S12, doi:10.1029/2007JA012743, 2008.

Bogdanova, Y. V., Marchaudon, A., Owen, C. J., Dunlop, M. W., Frey, H. U., Wild, J. A., Fazakerley, A. N., Klecker, B., Davies, J. A., and Milan, S. E.: On the formation of the highaltitude stagnant cusp: Cluster observations, Geophys. Res. Lett., 32, L12101, doi:10.1029/2005GL022813, 2005.

Bogdanova, Y. V., Owen, C. J., Dunlop, M. W., Wild, J. A., Davies, J. A., Lahiff, A. D., Taylor, M. G. G., Fazakerley, A. N., Dandouras, I., Carr, C. M., Lucek, E. A., and Rème, H.: Formation of the Low-Latitude Boundary Layer and Cusp under the northward IMF: conjugated observations by Cluster and Double Star, J. Geophys. Res., 113, A07S07, doi:10.1029/2007JA012762, 2008.

Borovsky, J. E.: The rudiments of a theory of solarwind/magnetosphere coupling derived from first principles, J. Geophys. Res., 113, A08228, doi:10.1029/2007JA012646, 2008.
Carr, C., Brown, P., Zhang, T. L., Gloag, J., Horbury, T., Lucek, E., Magnes, W., O’Brien, H., Oddy, T., Auster, U., Austin, P., Aydogar, O., Balogh, A., Baumjohann, W., Beek, T., Eichelberger, H., Fornacon, K.-H., Georgescu, E., Glassmeier, K.-H., Ludlam, M., Nakamura, R., and Richter, I.: The Double Star magnetic field investigation: instrument design, performance and highlights of the first year's observations, Ann. Geophys., 23, 27132732, doi:10.5194/angeo-23-2713-2005, 2005.

Cooling, B. M. A., Owen, C. J., and Schwartz, S. J.: Role of magnetosheath flow in determining the motion of open flux tubes, J. Geophys. Res., 106, 18763-18775, 2001.

Cowley, S. W. H.: A quantitative study of the reconnection between the earth's field and the interplanetary field of arbitrary orientation, Radio Sci., 8, 903-913, 1973.

Cowley, S. W. H.: On the possibility of magnetic fields and fluid flows parallel to the $X$-line in a re-connection geometry, J. Plasma Phys., 12, 319-339, 1974a.

Cowley, S. W. H.: Convection-region solutions for the re-connexion of antiparallel magnetic fields of unequal magnitude in an incompressible plasma, J. Plasma Phys., 12, 341-352, 1974 b.

Cowley, S. W. H.: Comment on the merging of non-antiparallel magnetic field, J. Geophys. Res., 81, 3455-3458, 1976.

Craig, I. J. D. and Henton, S. M.: Exact solutions for steady state incompressible magnetic reconnection, Astrophys. J., 450, 280288, 1995.

Crooker, N.: Dayside merging and cusp geometry, J. Geophys. Res., 84, 951-959, 1979.

Crooker, N., Lyon, J. G., and Fedder, J. A.: MHD model merging with IMF $B_{\mathrm{y}}$ : Lobe cells, sunward polar cap convection, and overdraped lobes, J. Geophys. Res., 103, 9143-9151, 1998.

Dorelli, J. C. and Raeder, J.: On the IMF clock angle dependence of the dayside magnetopause reconnection rate, Fall AGU Meeting, San Francisco, 2005.

Dorelli, J. C., Hesse, M., Kuznetsova, M., Rastaetter, L., and Reader, J.: A new look at driven magnetic reconnection at the terrestrial subsolar magnetopause, J. Geophys. Res., 109, A12216, doi:1029/2004JA010458, 2004.

Dorelli, J. C., Bhattacharjee, A., and Raeder, J.: Separator reconnection at Earth's dayside magnetopause under generic northward interplanetary magnetic field conditions, J. Geophys. Res., 112, A02202, doi:10.1029/2006JA011877, 2007.

Drake, J. F., Biskamp, D., and Zeiler, A.: Breakup of the electron current layer during 3-D collisionless magnetic reconnection, Geophys. Res. Lett., 24, 2921-2924, 1997.

Dungey, J. W.: Interplanetary magnetic field and the auroral zones, Phys. Rev. Lett., 6, 47-48, 1961.

Dunlop, M. W., Taylor, M. G. G. T., Davies, J. A., Owen, C. J., Pitout, F., Fazakerley, A. N., Pu, Z., Laakso, H., Bogdanova, Y. V., Zong, Q.-G., Shen, C., Nykyri, K., Lavraud, B., Milan, S. E., Phan, T. D., Rème, H., Escoubet, C. P., Carr, C. M., Cargill, P., Lockwood, M., and Sonnerup, B.: Coordinated Cluster/Double Star observations of dayside reconnection signatures, Ann. Geophys., 23, 2867-2875, doi:10.5194/angeo-23-2867-2005, 2005.

Dunlop, M. W., Taylor, M. G. G. T., Bogdanova, Y. V., Shen, C., Pitout, F., Pu, Z., Zhang, Q.-H., Davies, J. A., Lavraud, B., Fazakerley, A. N., Walsh, A., Owen, C. J., Laakso, H., Zong, Q.-G., Liu, Z.-X., Escoubet, C. P., Carr, C. M., and Rème, H.: Electron structure in the magnetopause boundary layer: Cluster/Double Star Observations, J. Geophys. Res., 113, A07S19, 
doi:10.1029/2007JA012788, 2008.

Dunlop, M. W., Zhang, Q.-H., Xiao, C.-J., Pu, Z., Fear, R., Shen, C., Escoubet, C. P.: Reconnection at high latitudes: dayside anti-parallel merging, Phys. Rev. Lett., 102, 075005, doi:10.1103/PhysRevLett.102.075005, 2009.

Dunlop, M. W., Zhang, Q.-H., Bogdanova, Y. V., Lockwood, M., Pu, Z., Hasegawa, H., Wang, J., Taylor, M. G. G. T., Berchem, J., Lavraud, B., Eastwood, J., Volwerk, M., Shen, C., Shi, J.-K., Constantinescu, D., Frey, H., Fazakerley, A. N., Sibeck, D., Escoubet, P., and Wild, J.: Extended magnetic reconnection across the dayside magnetopause, 107, 025004, doi:10.1103/PhysRevLett.107.025004, 2011.

Escoubet, C. P., Fehringer, M., and Goldstein, M.: Introduction: The Cluster mission, Ann. Geophys., 19, 1197-1200, doi:10.5194/angeo-19-1197-2001, 2001.

Fazakerley, A. N., Carter, P. J., Watson, G., Spencer, A., Sun, Y. Q., Coker, J., Coker, P., Kataria, D. O., Fontaine, D., Liu, Z. X., Gilbert, L., He, L., Lahiff, A. D., Mihalčič, B., Szita, S., Taylor, M. G. G. T., Wilson, R. J., Dedieu, M., and Schwartz, S. J.: The Double Star Plasma Electron and Current Experiment, Ann. Geophys., 23, 2733-2756, doi:10.5194/angeo-23-2733-2005, 2005.

Fear, R. C., Milan, S. E., Fazakerley, A. N., Fornaçon, K.-H., Carr, C. M., and Dandouras, I.: Simultaneous observations of flux transfer events by THEMIS, Cluster, Double Star, and SuperDARN: Acceleration of FTEs, J. Geophys. Res., 114, A10213, doi:10.1029/2009JA014310, 2009.

Fujimoto, M., Nakamura, M. S., Shinohara, I., Nagai, T., Mukai, T., Saito, Y., Yamamoto, T., and Kokubun, S.: Observations of earthward streaming electrons at the trailing boundary of a plasmoid, Geophys. Res. Lett., 24, 2893-2896, doi:10.1029/97GL02821, 1997.

Gonzalez, W. D. and Mozer, F. S.: A quantitative model for the potential resulting from reconnection with an arbitrary interplanetary magnetic field, J. Geophys. Res., 79, 4186-4194, 1974.

Haerendel, G., Paschmann, G., Sckopke, N., Rosenbauer, H., and Hedgecock, P.: The Frontside Boundary Layer of the Magnetosphere and the Problem of Reconnection, J. Geophys. Res., 83, 3195-3216, 1978.

Hasegawa H., Fujimoto, M., Phan, T. D., Rème, H., Balogh, A., Dunlop, M. W., Hashimoto, C., and TanDokoro, R.: Transport of solar wind into Earth's magnetosphere through rolled-up KelvinHelmholtz vortices, Nature, 430, 755-758, 2004a.

Hasegawa, H., Sonnerup, B. U. Ö., Dunlop, M. W., Balogh, A., Haaland, S. E., Klecker, B., Paschmann, G., Lavraud, B., Dandouras, I., and Rème, H.: Reconstruction of two-dimensional magnetopause structures from Cluster observations: verification of method, Ann. Geophys., 22, 1251-1266, doi:10.5194/angeo22-1251-2004, 2004b.

Hasegawa, H., Wang, J., Dunlop, M. W., Pu, Z. Y., Zhang, Q.H., Lavraud, B., Taylor, M. G. G. T., Constantinescu, O. D., Berchem, J., Angelopoulos, V., McFadden, J. P., Frey, H. U., Panov, E. V., Volwerk, M., and Bogdanova, Y. V.: Evidence for a flux transfer event generated by multiple $\mathrm{X}$-line reconnection at the magnetopause, Geophys. Res. Lett., 37, L16101, doi:10.1029/2010GL044219, 201.

Hesse, M. and Schindler, K.: A Theoretical Foundation of General Magnetic Reconnection, J. Geophys. Res., 93, 5559-5567, 1988.

Johnstone, A. D., Alsop, C., Burdge, S., Carter, P. J., Coates, A. J., Coker, A. J., and Fazakerley, A.: Plasma elec- tron and current experiment, Space Sci. Rev., 79, 351-398, doi:10.1023/A:1004938001388, 1997.

Kessel, R. L., Chen, S.-H., Green, J. L., Fung, S. F., Boardsen, S. A., Tan, L. C., Eastman, T. E., Craven, J. D., and Frank, L. A.: Evidence of high-latitude reconnecting during northward IMF: Hawkeye observations, Geophys. Res. Lett., 23, 583-586, 1996.

Lavraud, B. and Borovsky, J. E.: Altered solar wind-magnetosphere interaction at low Mach numbers: Coronal mass ejections, J. Geophys. Res., 113, A00B08, doi:10.1029/2008JA013192, 2008.

Lavraud, B., Fedorov, A., Budnik, E., Grigoriev, A., Cargill, P. J., Dunlop, M. W., Rème, H., Dandouras, I., and Balogh, A.: Cluster survey of the high-altitude cusp properties: a three-year statistical study, Ann. Geophys., 22, 3009-3019, doi:10.5194/angeo22-3009-2004, 2004.

Lavraud, B., Fedorov, A., Budnik, E., Thomsen, M. F., Grigoriev, A., Cargill, P. J., Dunlop, M. W., Rème, H., Dandouras, I., and Balogh, A.: High-altitude cusp flows dependence on IMF orientation: A three-year Cluster statistical study, J. Geophys. Res., 110, A02209, doi:10.1029/2004JA010804, 2005a.

Lavraud, B., Thomsen, M. F., Taylor, M. G. G. T., Wang, Y. L., Phan, T. D., Schwartz, S. J., Elphic, R. C., Fazakerley, A., Rème, H., and Balogh, A.: Characteristics of the magnetosheath electron boundary layer under northward IMF: Implications for high-latitude reconnection, J. Geophys. Res., 110, A06209, doi:10.1029/2004JA010808, 2005b.

Lavraud, B., Thomsen, M. F., Lefebvre, B., Schwartz, S. J., Seki, K., Phan, T. D., Wang, Y. L., Fazakerley, A., Rème, H., and Balogh, A.: Evidence for newly closed magnetosheath field lines at the dayside magnetopause under northward IMF, J. Geophys. Res., 111, A05211, doi:10.1029/2005JA011266, 2006.

Liu, Z. X., Escoubet, C. P., Pu, Z., Laakso, H., Shi, J. K., Shen, C., and Hapgood, M.: The Double Star mission, Ann. Geophys., 23, 2707-2712, doi:10.5194/angeo-23-2707-2005, 2005.

Lockwood, M. and Hapgood, M. A.: On the cause of a magnetospheric flux transfer event, J. Geophys. Res., 103, 26453-26478, 1998.

Lockwood, M. and Smith, M. F.: The variation of reconnection rate at the dayside magnetopause and cusp ion precipitation, J. Geophys. Res., 97, 14841-14847, 1992.

McFadden, J. P., Carlson, C. W., Larson, D., Angelopolos, V., Ludlam, M., Abiad, R., and Elliot, B.: The THEMIS ESA plasma instrument and in-flight calibration, Space Sci. Rev., 141, 277 302, 2008.

Moore, T. E., Fok, M.-C., and Chandler, M. O.: The dayside reconnection X line, J. Geophys. Res., 107, 1332-1339, 2002.

Mozer, F. S., Bale, S. D., and Phan, T. D.: Evidence of Diffusion Regions at a Subsolar Magnetopause Crossing, Phys. Rev. Lett., 89, 015002, doi:10.1103/PhysRevLett.89.015002, 2002.

Nishida, A.: Can random reconnection on the magnetopause produce the low latitude boundary layer?, Geophys. Res. Lett., 16, 227-230, 1989.

Nishino, M. N., Hasegawa, H., Fujimoto, M., Saito, Y., Mukai, T., and Dandouras, I.: A case study of Kelvin-Helmholtz vortices on both flanks of the Earth's magnetotail, Planet. Space Sci., 59, 502, doi:10.1016/j.pss.2010.03.011, 2011

Oiereset, T., Phan, D., Fujimoto, M., Lin, R. P., and Lepping, R. P.: In situ detection of collisionless reconnection in the Earth's magnetotail, Nature, 412, 414-417, 2001. 
Onsager, T. G., Scudder, J. D., Lockwood, M., and Russell, C. T.: Reconnection at the high latitude magnetopause during northward interplanetary magnetic field conditions, J. Geophys. Res., 106, 25467-25488, 2001.

Owen, C. J., Marchaudon, A., Dunlop, M. W., Fazakerley, A. N., Bosqued, J. M., Dewhurst, J. P., Fear, R., Fuselier, S. A., Balogh, A., and Reme, H.: Cluster observations of 'Crater' Flux Transfer Events at the Dayside High-Latitude Magnetopause, J. Geophys. Res., 113, A07S04, doi:10.1029/2007JA012701, 2008.

Paschmann, G.: Recent in-situ observations of magnetic reconnection in near-Earth space, Geophys. Res. Lett., 35, L19109, doi:10.1029/2008GL035297, 2008.

Paschmann, G., Sonnerup, B. U. O., Papamastorakis, I., Sckopke, N., Haerendel, G., Bame, S. J., Asbridge, J. R., Gosling, J. T., Russell, C. T., and Elphic, R. C.: Plasma acceleration at the earth's magnetopause: Evidence for reconnection, Nature, 282, 243-246, 1979.

Phan, T. D., Dunlop, M. W., Paschmann, G., Klecker, B., Bosqued, J. M., Rème, H., Balogh, A., Twitty, C., Mozer, F. S., Carlson, C. W., Mouikis, C., and Kistler, L. M.: Cluster observations of continuous reconnection at the magnetopause under steady interplanetary magnetic field conditions, Ann. Geophys., 22, 23552367, doi:10.5194/angeo-22-2355-2004, 2004.

Phan, T.-D., Paschmann, G., Twitty, C., Mozer, F. S., Gosling, J. T., Eastwood, J. P., Øieroset, M., Rème, H., and Lucek, E. A.: Evidence for magnetic reconnection initiated in the magnetosheath, Geophys. Res. Lett., 34, L14104, doi:10.1029/2007GL030162, 2007.

Pu, Z. Y., Xiao, C. J., Zhang, X. G., Huang, Z. Y., Fu, S. Y., Liu, Z. X., Dunlop, M. W., Zong, Q. G., Carr, C. M., Réme, H., Dandouras, I., Fazakerley, A., Phan, T., Zhang, T. L., Zhang, H., and Wang, X. G.: Double Star TC-1 observations of component reconnection at the dayside magnetopause: a preliminary study, Ann. Geophys., 23, 2889-2895, doi:10.5194/angeo-232889-2005, 2005.

Pu, Z.-Y., Zhang, X. G., Wang, X. G., Zhou, X.-Z., Xie, L., Dunlop, M. W., Zong, Q. G., Xiao, C. J., Wang, J., Fu, S. Y., Liu, Z. X., Shen, C., Lucek, E., Carr, C., and Rème, H.: Global view of dayside magnetic reconnection with the dawn-dusk IMF orientation: a statistic study for TC-1 and Cluster data, Geophys. Res. Lett., 34, L20101, doi:10.1029/2007GL030336, 2007.

Rème, H., Aoustin, C., Bosqued, J. M., Dandouras, I., Lavraud, B., Sauvaud, J. A., Barthe, A., Bouyssou, J., Camus, Th., CoeurJoly, O., Cros, A., Cuvilo, J., Ducay, F., Garbarowitz, Y., Medale, J. L., Penou, E., Perrier, H., Romefort, D., Rouzaud, J., Vallat, C., Alcaydé, D., Jacquey, C., Mazelle, C., d'Uston, C., Möbius, E., Kistler, L. M., Crocker, K., Granoff, M., Mouikis, C., Popecki, M., Vosbury, M., Klecker, B., Hovestadt, D., Kucharek, H., Kuenneth, E., Paschmann, G., Scholer, M., Sckopke, N., Seidenschwang, E., Carlson, C. W., Curtis, D. W., Ingraham, C., Lin, R. P., McFadden, J. P., Parks, G. K., Phan, T., Formisano, V., Amata, E., Bavassano-Cattaneo, M. B., Baldetti, P., Bruno, R., Chionchio, G., Di Lellis, A., Marcucci, M. F., Pallocchia, G., Korth, A., Daly, P. W., Graeve, B., Rosenbauer, H., Vasyliunas, V., McCarthy, M., Wilber, M., Eliasson, L., Lundin, R., Olsen, S., Shelley, E. G., Fuselier, S., Ghielmetti, A. G., Lennartsson, W., Escoubet, C. P., Balsiger, H., Friedel, R., Cao, J.-B., Kovrazhkin, R. A., Papamastorakis, I., Pellat, R., Scudder, J., and Sonnerup, B.: First multispacecraft ion measurements in and near the Earth's magnetosphere with the identical Cluster ion spectrometry (CIS) experiment, Ann. Geophys., 19, 1303-1354, doi:10.5194/angeo19-1303-2001, 2001.

Rème, H., Dandouras, I., Aoustin, C., Bosqued, J. M., Sauvaud, J. A., Vallat, C., Escoubet, P., Cao, J. B., Shi, J., BavassanoCattaneo, M. B., Parks, G. K., Carlson, C. W., Pu, Z., Klecker, B., Moebius, E., Kistler, L., Korth, A., Lundin, R., and the HIA team: The HIA instrument on board the Tan Ce 1 Double Star near-equatorial spacecraft and its first results, Ann. Geophys., 23, 2757-2774, doi:10.5194/angeo-23-2757-2005, 2005.

Retinò, A., Bavassano Cattaneo, M. B., Marcucci, M. F., Vaivads, A., André, M., Khotyaintsev, Y., Phan, T., Pallocchia, G., Rème, H., Möbius, E., Klecker, B., Carlson, C. W., McCarthy, M., Korth, A., Lundin, R., and Balogh, A.: Cluster multispacecraft observations at the high-latitude duskside magnetopause: implications for continuous and component magnetic reconnection, Ann. Geophys., 23, 461-473, doi:10.5194/angeo-23-461-2005, 2005.

Russell, C. T. and Elphic, R. C.: Initial ISEE magnetometer results: magnetopause observations, Space Sci. Rev., 22, 681-715, 1978.

Scurry, L. and Russell, C. T.: Proxy studies of energy transfer to the magnetosphere, J. Geophys. Res., 96, 9541-9548, doi:10.1029/91JA00569, 1991.

Shue, J.-H., Song, P., Russell, C. T., Steinberg, J. T., Chao, J. K., Zastenker, G., Vaisberg, O. L., Kokubun, S., Singer, H. J., and Detman, T. R.: Magnetopause location under extreme solar wind conditions, J. Geophys. Res., 103, 17691-17700, 1998.

Sibeck, D. G., Lopez, R. E., and Roelof, E. C.: Solar wind control of the magnetopause shape location and motion, J. Geophys. Res., 96, 5489-5495, 1991.

Smith, C. W., Acuna, M. H., Burlaga, L. F., L'Heureux, J., Ness, N. F., and Scheifele, J.: The ACE Magnetic Fields Experiment, Space Sci. Rev., 86, 613-631, 1998.

Sonnerup, B. U. Ö.: Magnetic field reconnection in a highly conducting incompressible fluid, J. Plasma Phys., 4, 207-229, 1970.

Sonnerup, B. U. Ö.: The magnetopause reconnection rate, J. Geophys. Res., 79, 1546-1549, 1974.

Sonnerup, B. U. Ö., Paschmann, G., Papamastorakis, I., Sckopke, N., Haerendel, G., Bame, S. J., Asbridge, J. R., Gosling, J. T., and Russell, C. T.: Evidence for magnetic field reconnection at the Earth's magnetopause, J. Geophys. Res., 86, 10049-10067, 1981.

Swisdak, M., Drake, J. F., Shay, M. A., and McIlhargey, J. G.: Transition from antiparallel to component magnetic reconnection, J. Geophys. Res., 110, A05210, doi:10.1029/2004JA010748, 2005.

Taylor, M. G. G. T. and Lavraud, B.: Observation of three distinct ion populations at the Kelvin-Helmholtz-unstable magnetopause, Ann. Geophys., 26, 1559-1566, doi:10.5194/angeo-261559-2008, 2008.

Taylor, M. G. G. T., Lavraud, B., Escoubet, C. P., Milan, S. E., Nykyri, K., Dunlop, M. W., Davies, J. A., Friedel, R. H. W., Frey, H., Bogdanova, Y. V., Åsnes, A., Laakso, H., Trávnićek, P., Masson, A., Opgenoorth, H., Vallat, C., Fazakerley, A. N., Lahiff, A. D., Owen, C. J., Pitout, F., Pu, Z., Shen, C., Zong, Q. G., Rème, H., Scudder, J., and Zhang, T. L.: The plasma sheet and boundary layers under northward IMF: a multi-point and multi-instrument perspective, Adv. Space Res., 41, 16191629, doi:10.1016/j.asr.2007.10.013, 2007.

Trattner, K. J., Fuselier, S. A., and Petrinec, S. M.: Location of the 
reconnection line for northward interplanetary magnetic field, J. Geophys. Res., 109, A03219, doi:10.1029/2003JA009975, 2004.

Trattner, K. J., Mulcock, J. S., Petrinec, S. M., and Fuselier, S. A.: Probing the boundary between antiparallel and component reconnection during southward interplanetary magnetic field conditions, J. Geophys. Res., 112, A08210, doi:10.1029/2007JA012270, 2007.

Twitty, C., Phan, T. D., Paschmann, G., Lavraud, B., Rème, H., and Dunlop, M.: Cluster survey of cusp reconnection and its IMF dependence, Geophys. Res. Lett., 31, L19808, doi:10.1029/2004GL020646, 2004.

Vaivads, A., Khotyaintsev, Y., André, M., Retinò, A., Buchert, S. C., Rogers, B. N., Décréau, P., Paschmann, G., and Phan, T. D.: Structure of the Magnetic Reconnection Diffusion Region from Four-Spacecraft Observations, Phys. Rev. Lett., 93, 105001, doi:10.1103/PhysRevLett.93.105001, 2004.
Wang, J., Dunlop, M. W., Pu, Z. Y., Zhou, X. Z., Zhang, X. G., Wei, Y., Fu, S. Y., Xiao, C. J., Fazakerley, A., Laakso, H., Taylor, M. G. G. T., Bogdanova, Y., Pitout, F., Davies, J., Zong, Q. G., Shen, C., Liu, Z. X., Carr, C., Perry, C., Rème, H., Dandouras, I., Escoubet, P., and Owen, C. J.: TC1 and Cluster observation of an FTE on 4 January 2005: A close Conjunction, Geophys. Res. Lett., 34, L03106, doi:10.1029/2006GL028241, 2007.

Wild, J. A., Milan, S. E., Davies, J. A., Dunlop, M. W., Wright, D. M., Carr, C. M., Balogh, A., Rème, H., Fazakerley, A. N., and Marchaudon, A.: On the location of dayside magnetic reconnection during an interval of duskward oriented IMF, Ann. Geophys., 25, 219-238, doi:10.5194/angeo-25-219-2007, 2007. 